\title{
A New Montmorillonite/Humic Acid Complex Prepared in Alkaline Condition to Remove Cadmium in Waste Water
}

\author{
Xiangfeng Zeng ${ }^{1,2,3}$, Zuwei Wang ${ }^{2 *}$, Zhanhua $\mathrm{Ji}^{1,2,3}$, Shuhe Wei ${ }^{1}$ \\ 'Key Laboratory of Pollution Ecology and Environmental Engineering, Institute of Applied Ecology, \\ Chinese Academy of Sciences, Shenyang 110016, P.R. China \\ ${ }^{2}$ College of Urban and Environment Science, Tianjin Normal University, Tianjin 300384, PR China \\ ${ }^{3}$ University of Chinese Academy of Sciences, Beijing 100039, P.R. China
}

Received: 20 February 2014

Accepted: 3 August 2014

\begin{abstract}
A new montmorillonite/humic acid complex preparation method in the alkaline environment was studied by experiment, and the complex effect on remediation of heavy metal pollution was verified. The best technological condition of the montmorillonite/humic acid complex preparation in alkaline environment was that the mass ratio between montmorillonite and humic acid was 100:3, the reaction solution was $0.01 \mathrm{~mol} / \mathrm{L}$ sodium nitrate solution, the $\mathrm{pH}$ value of the reaction solution was 8.5 , and the reaction time was 24 hours. The complex has better remediation effect on cadmium waste water. The cadmium adsorption capacity of the complex was $18.96 \mathrm{mg} / \mathrm{g}$, and the $\mathrm{pH}$ value ranges of cadmium waste water suited for the complex was from 5 to 9 .
\end{abstract}

Keywords: montmorillonite/humic acid complex, alkaline environment, removal effect, cadmium waste water

\section{Introduction}

Clay minerals, as an aggregate of minerals and colloidal substances, are hydrous aluminosilicate minerals that dominantly make up the colloid fraction $(<200 \mathrm{~nm})$ of soils, sediments, rocks, and water beings [1-3]. The large surface area, cation exchange capacity (CEC), high abundance and local availability, non toxicity, chemical and mechanical stability, Brønsted and Lewis acidity, low costs, ability to be recycled, layered structure, etc., determine the usefulness of clays as a natural cleaning agent [4-6]. Montmorillonite, one of the most widely used clays, has been proven efficient in removal of heavy metals, including $\mathrm{Cd}$, which is of great concern because of the increasing trend in discharge, nondegradation in nature, and high toxicity to plants, animals, and human beings $[1,7,8]$.

*e-mail: shidalvwo@126.com
There is growing interest in research on improving the removal of heavy metal ions from industrial wastewaters $[9,10]$. Various attempts have been made to improve the quality and characteristics of the clays such as using acid activation under high temperature, and replacing the interlayer inorganic cations with $\mathrm{Fe}(\mathrm{III})$ nitrate, aliphatic, and aromatic ammonium bromide [11-13]. Some researchers have reported that modification by humic acid could enhance the adsorption capacities of the clays [14]. In fact, humic acid with a negative charge has high cation exchange capacity and good complex performance and has a significant role in adsorption of heavy metals, and clay minerals can combine with humic acids to form organic/inorganic complex, and the complex can react with pollutants in the environment $[14,15]$.

At present, most organic/inorganic complexes were obtained and used to remove the heavy metals in neutralacid condition. Arias et al. studied the characteristics of 
copper and cadmium on kaolin by the presence of humic acids and the selected experimental $\mathrm{pH}$ values ranging from 4 to 7 [14]; Belghiti et al. selected $\mathrm{pH}$ values ranging from 4 to 7 as the experimental condition to study the $\mathrm{pH}$ effect on imazethapyr adsorption onto montmorillonite (M), $\mathrm{Cu}$ montmorillonite $(\mathrm{Cu}-\mathrm{M})$, and $\mathrm{Cu}$ humicacid-montmorillonite (Cu-HA-M) [16]. Other authors' experimental $\mathrm{pH}$ conditions were similar to bromide [17-20]. However, very few studies have investigated preparation of complexes in an alkaline environment. There also is no information on effects of the complex on remediation of heavy metals in alkaline environment. The objective of this study was to:

(1) Prepare a new montmorillonite/humic acid complex preparation method in alkaline environment

(2) Use it to remove cadmium from wastewater

\section{Experiments}

Chemicals

Montmorillonite, Cadmium nitrate, and humic acid were purchased from Sigma-Aldrich (St. Louis, MO). Potassium chloride, sodium hydroxide, and nitric acid were purchased from Lach Ner (Brno, Czech Republic). All chemicals were of analytical reagent grade. Deionized water was supplied from a Milli-Q water purification system (Millipore, Bedford, MA).

Montmorillonite/Humic Acid Complex Preparation Technological Parameters Selection

\section{Reaction Time}

Put $0.2 \mathrm{~g}$ montmorillonite each into nine Erlenmeyer flasks and pour $20 \mathrm{~mL}$ quality concentration $300 \mathrm{mg} / \mathrm{L}$ humic sodium solutions into each flask in which the $\mathrm{pH}$ values of the solutions were 8.5 , make the reaction in constant temperature oscillator at $298 \mathrm{~K}$, set reaction time to 10 min, 30 min, 1 h, 2 h, 3 h, 4 h, 6 h, 12 h, 24 h, 36 h, respectively. When time's out, centrifuge the flasks and collect the supernatant and analyze the concentration of humic acid by spectrophotometer.

\section{Mass Ratio between Montmorillonite and Humic Acid}

Put $0.2 \mathrm{~g}$ montmorillonite each into 6 Erlenmeyer flasks, pour $20 \mathrm{~mL}$ humic sodium solutions into each flask and the humic acid quality concentration of solutions was $10,50,100,200,300$, and $500 \mathrm{mg} / \mathrm{L}$, respectively, in which the $\mathrm{pH}$ values of the solutions were 8.5 , set the reaction time $24 \mathrm{~h}$. When time's out, centrifuge the flasks and collect the supernatant and analyze the concentration of humic acid by spectrophotometer.

\section{Ionic Concentration in Reaction Solution}

Put 0.2 g montmorillonite into 7 Erlenmeyer flasks respectively, pour $20 \mathrm{~mL}$ quality concentration $300 \mathrm{mg} / \mathrm{L}$ humic sodium solutions in which the $\mathrm{pH}$ values of the solutions were 8.5 and the ion concentrations of sodium nitrate in the reaction solutions were $0,0.005,0.01,0.025,0.05$, $0.1,0.5 \mathrm{~mol} / \mathrm{L}$, respectively, and make the reactions in constant temperature oscillator at $298 \mathrm{~K}$ and set reaction time to 24 hours.

\section{pH Value Selection}

Put $0.2 \mathrm{~g}$ montmorillonite each into Erlenmeyer flasks pour $20 \mathrm{~mL}$ quality concentration $300 \mathrm{mg} / \mathrm{L}$ humic sodium solutions in which the $\mathrm{pH}$ values of the solutions were 2.5, $3,3.5,4,4.5,5,6,7,8,8.5,9$, and 10 , and make the reactions in constant temperature oscillator at $298 \mathrm{~K}$ and set reaction time to 24 hours

\section{Remediation Effect Verification to Cadmium Waste Water by the Complex}

\section{The Time to Achieve Best Remediation Effect}

Put $0.2 \mathrm{~g}$ of the complex into $50 \mathrm{ml}$ Erlenmeyer flask and pour $20 \mathrm{~mL}$ quality concentration $60 \mathrm{mg} \cdot \mathrm{L}^{-1}$ cadmium waste water into the flask, and the $\mathrm{pH}$ value of the solution was 8 . Make the reactions in constant temperature oscillator at $298 \mathrm{~K}$ and set reaction time to $10 \mathrm{~min}, 30 \mathrm{~min}, 1 \mathrm{~h}, 2$ h, $4 \mathrm{~h}, 8 \mathrm{~h}$, and $16 \mathrm{~h}$. When time's out, centrifuge the flasks and collect the supernatant and analyze the concentration of cadmium by ICP-MS. The removal ratio of cadmium in waste water is calculated as follows:

$$
Q=\left(M_{0}-C V\right) / M_{0} \times 100 \%
$$

...where $Q$ is removal ratio of $\mathrm{Cd}[\%], M_{0}$ is Cd initiate concentration $\left[\mathrm{mg} \cdot \mathrm{L}^{-1}\right], C$ is the quality concentration of cadmium in the supernatant after reaction $\left[\mathrm{mg} \cdot \mathrm{L}^{-1}\right]$, and $V$ is volumes [L].

\section{Adsorption Capacity}

Put $0.2 \mathrm{~g}$ of the complex into each $50 \mathrm{ml}$ Erlenmeyer flask and pour $20 \mathrm{~mL}$ cadmium quality concentration 7.5 $\mathrm{mg} \cdot \mathrm{L}^{-1}, 15 \mathrm{mg} \cdot \mathrm{L}^{-1}, 30 \mathrm{mg} \cdot \mathrm{L}^{-1}, 60 \mathrm{mg} \cdot \mathrm{L}^{-1}, 120 \mathrm{mg} \cdot \mathrm{L}^{-1}$, and $240 \mathrm{mg} \cdot \mathrm{L}^{-1}$ waste water into the flasks and the $\mathrm{pH}$ value of the solutions was 8 . Make the reactions in constant temperature oscillator at $298 \mathrm{~K}$ and set reaction time $2 \mathrm{~h}$. When time's out, centrifuge the flasks and collect the supernatant and analyze the concentration of cadmium by ICPMS.

\section{The Removal Effect of Cadmium in Waste Water with Different $p H$ Values}

Put $0.2 \mathrm{~g}$ the complex into each $50 \mathrm{ml}$ Erlenmeyer flask and pour $20 \mathrm{~mL}$ quality concentration $60 \mathrm{mg} \cdot \mathrm{L}^{-1}$ cadmium waste water into the flasks in which the $\mathrm{pH}$ values of the solutions were $5,6,7,8,9$, make the reactions in constant temperature oscillator at $298 \mathrm{~K}$ and set reaction time to $2 \mathrm{~h}$. 


\section{Results and Discussion}

\section{Best Complex Preparation Technological Parameters}

\section{Best Technological Parameters}

\section{- Best Reaction Time}

The change of humic acid adsorption by montmorillonite was shown in Fig. 1. The equilibrium time of humic acid adsorption on montmorillonite was about $24 \mathrm{~h}$ and the adsorption was $27 \mathrm{mg} / \mathrm{g}$. The best reaction time was selected for 24 hours during complex preparation in the experiment.

- Best Mass Ratio between Montmorillonite and Humic Acid

The influence of humic acid concentration in initiative solutions on mintmorillonite adsorption humic acid was shown in Fig. 2.

The adsorption of humic acid on montmorillonite gradually increased with the increase of initial concentration of

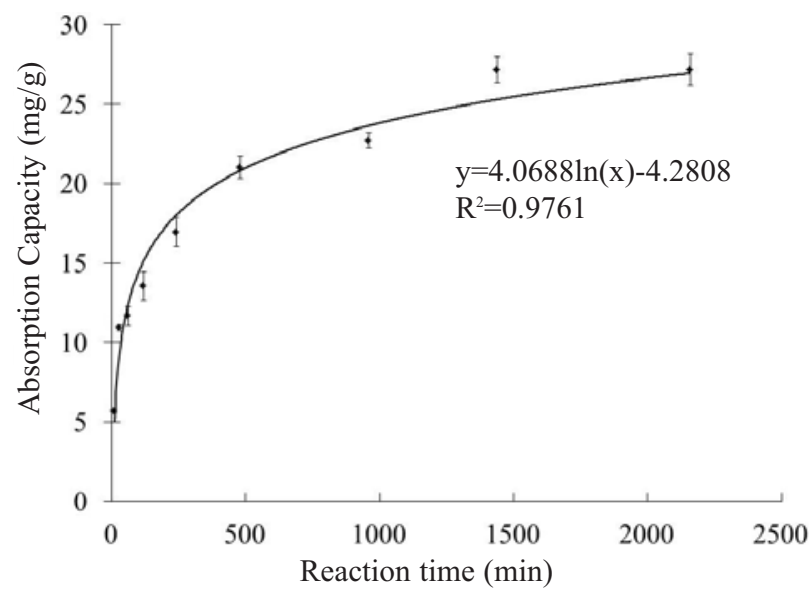

Fig. 1. Humic acid adsorption on mintmorillonite changed with reaction time.

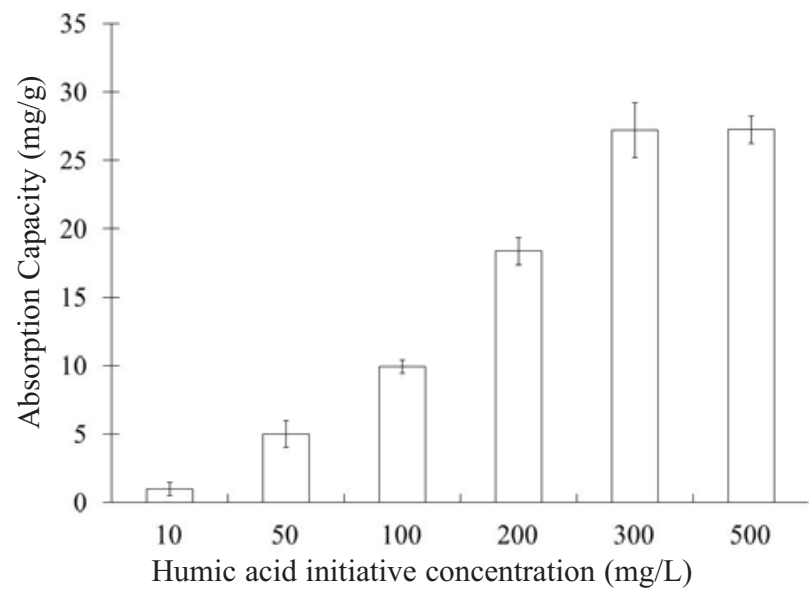

Fig. 2. The influence of humic acid initiative concentration.

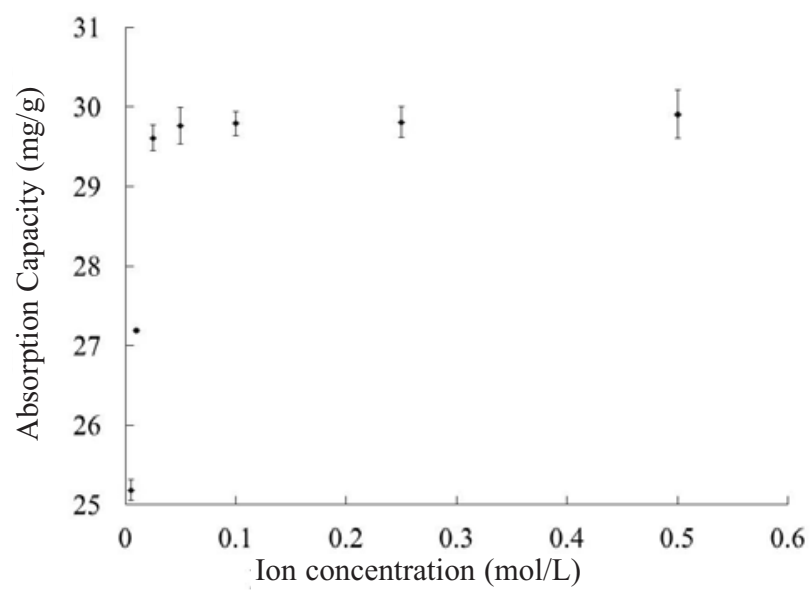

Fig. 3. Influence of Ionic concentration on reaction solution.

humic acid and when the concentration of humic acid was $300 \mathrm{ppm}$, the montmorillonite adsorption reached saturation. Mass ratio between montmorillonite and humic acid was selected for 100:3 during complex preparation in the experiment.

\section{- Best Ionic Concentration}

The influence of Ion concentration in reaction solution on montmorillonite-adsorbing humic acid was shown in Fig. 3.

The adsorption of humic acid on montmorillonite gradually increased with the increase of the ion concentration in reaction solution at the range of 0 to $0.025 \mathrm{~mol} / \mathrm{L}$, and the adsorption did not change after the ion concentration in reaction solution was over $0.025 \mathrm{~mol} / \mathrm{L}$. The ion concentration $0.025 \mathrm{~mol} / \mathrm{L}$ in reaction solution was selected during complex preparation.

- Best pH Value in the Solution

The influence of $\mathrm{pH}$ value on adsorption of humic acid by montmorillonite is shown in Table 1.

The adsorption of humic acid on montmorillonite in acid condition was high, but the adsorption decreased as $\mathrm{pH}$ value increased. When the $\mathrm{pH}$ value was at the range of 7 to 8.5 , the adsorption of humic acid on montmorillonite increased and the adsorption of humic acid on montmorillonite was highest when the $\mathrm{pH}$ value was 8.5 in alkaline condition. Because the experiment studies the montmorillonite/humic acid complex preparation method in alkaline conditions, 8.5 was selected as the $\mathrm{pH}$ value.

\section{The Montmorillonite/Humic Acid Complex Preparation}

Based on the experiment, the montmorillonite/ humic acid complex preparation method in alkaline condition was determined as follows:

Put $0.2 \mathrm{~g}$ montmorillonite into the Erlenmeyer flask and pour $20 \mathrm{~mL}$ quality concentration $300 \mathrm{mg} / \mathrm{L}$ humic sodium solutions in which the $\mathrm{pH}$ value of the solutions was 8.5 , 
Table 1. The influence of $\mathrm{pH}$ value on adsorption of humic acid by montmorillonite.

\begin{tabular}{|c|c|c|c|c|c|c|c|c|c|c|c|c|c|}
\hline \multicolumn{2}{|c|}{$\mathrm{pH}$} & 2.5 & 3 & 3.5 & 4 & 4.5 & 5 & 6 & 7 & 8 & 8.5 & 9 & 10 \\
\hline \multirow{4}{*}{$\begin{array}{c}\text { Adsorption } \\
\text { Capacity } \\
(\mathrm{mg} / \mathrm{g})\end{array}$} & Max-value & 26.30 & 25.80 & 26.22 & 26.14 & 26.22 & 26.08 & 23.11 & 18.82 & 23.66 & 27.11 & 26.27 & 21.18 \\
\hline & Min-value & 26.44 & 25.59 & 26.58 & 26.28 & 26.31 & 26.15 & 23.21 & 19.07 & 23.82 & 27.23 & 26.35 & 21.44 \\
\hline & Mean- & 26.32 & 25.7 & 26.32 & 26.24 & 26.17 & 26.02 & 23.15 & 18.99 & 23.74 & 27.18 & 26.35 & 21.38 \\
\hline & Standard errors & 0.020 & 0.51 & 0.05 & 7.33 & 0.10 & 0.14 & 0.029 & 0.58 & 0.17 & 4.59 & 0.16 & 0.31 \\
\hline
\end{tabular}

Table 2. The removal effect of the complex in different $\mathrm{pH}$ value ranges.

\begin{tabular}{|c|c|c|c|c|c|c|}
\hline \multicolumn{2}{|c|}{$\mathrm{pH}$} & 5 & 6 & 7 & 8 & 9 \\
\hline \multirow{4}{*}{$\begin{array}{c}\text { Removal Ratio } \\
(\%)\end{array}$} & Max-value & 96.08 & 96.89 & 96.13 & 99.18 & 99.29 \\
\cline { 2 - 8 } & Min-value & 96.25 & 97.02 & 96.27 & 99.29 & 99.44 \\
\cline { 2 - 8 } & Mean-value & 96.20 & 96.98 & 96.21 & 99.22 & 99.34 \\
\cline { 2 - 8 } & Standard Errors & 0.11 & 1.51 & 0.62 & 0.43 & 0.98 \\
\hline
\end{tabular}

and the ion concentrations of sodium nitrate in the reaction solutions was $0.01 \mathrm{~mol} / \mathrm{L}$. Make the reactions start in a constant temperature oscillator at $298 \mathrm{~K}$ and set reaction time to 24 hours. The solid particle was gained after the Erlenmeyer flask was centrifuged. The montmorillonite/ humic acid complex was gained after the solid particle was washed and air-dried.

\section{The Remediation Effect to the Cadmium Waste Water by the Complex}

\section{The Time to Achieve Best Remediation Effect}

The removal effect of the complex to cadmium in different times was shown in Fig. 4. The cadmium removeal effect of the complex was better in 2 hours, and the removal ratio of cadmium was over $99 \%$.

\section{The Removal Ratios of Cadmium in Waste Water in Different Initial Concentrations}

The removal ratios of cadmium in waste water in different initial concentrations were calculated, and the result was shown in Fig. 5.

The removal ratios of cadmium in waste water was higher than $99.5 \%$, when cadmium initial concentration in the waste water was $60 \mathrm{mg} \cdot \mathrm{L}^{-1}$. The cadmium adsorption capacity by the complex can be $18.96 \mathrm{mg} / \mathrm{g}$, in which the cadmium initial concentration was $120 \mathrm{mg} \cdot \mathrm{L}^{-1}$.

\section{The Removal Effect of Cadmium in Waste Water with Different $p H$ Values}

The removal ratio of cadmium by the complex in waste water of different $\mathrm{pH}$ values was shown in Table 2 . The removal ratios of cadmium in different $\mathrm{pH}$ values were

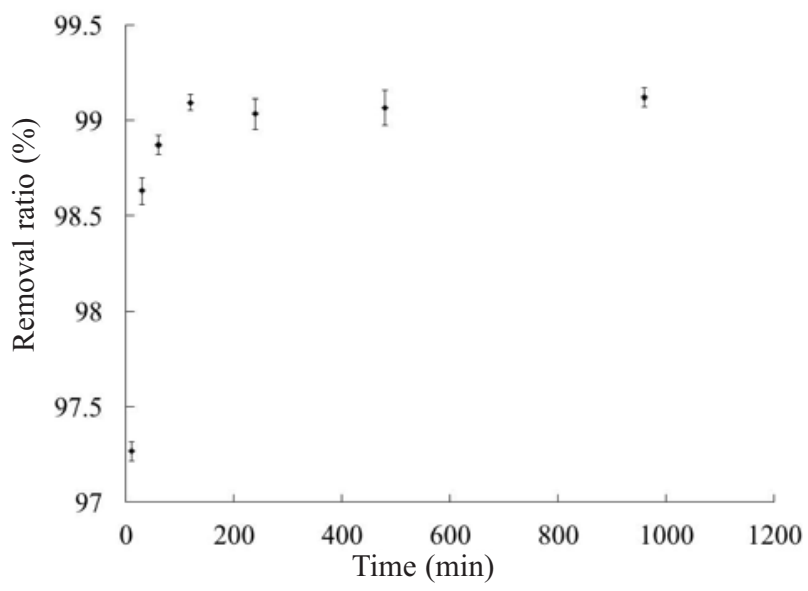

Fig. 4. Cadmium removal effect by the complex with time.



Fig. 5. Influence of cadmium initial concentration on the removal ratio by the complex. 
higher, and the effect was obvious when the $\mathrm{pH}$ value of the waste water was higher than 8 . There is wider $\mathrm{pH}$ value range that the complex can use to remove cadmium from the waste water.

\section{The Benefit of the Method}

To compare with other complexes, the cadmium adsorption capacity of the complex was three times other complexes (cadmium adsorption capacity ranging from 6 to $7 \mathrm{mg} / \mathrm{g}$ ), the $\mathrm{pH}$ value ranges from 5 to 9 , which was wider than other complexes ( $\mathrm{pH}$ value ranging from 4 to 6 ) and can be used in alkaline environment.

\section{Conclusions}

The best technological condition of montmorillonite/ humic acid complex preparation was that the mass ratio between montmorillonite and humic acid was 100:3, the reaction solution was $0.01 \mathrm{~mol} / \mathrm{L}$ sodium nitrate solution, $\mathrm{pH}$ value of the reaction solution was 8.5 , and the reaction time was 24 hours.

The complex has a better remediation effect to cadmium in waste water and it can be used in wide $\mathrm{pH}$ value ranges from 5 to 9 . The cadmium adsorption capacity of the complex was $18.96 \mathrm{mg} / \mathrm{g}$.

To compare with other complexes, the cadmium adsorption capacity of the complex was three times other complexes (cadmium adsorption capacity ranging from 6 to $7 \mathrm{mg} / \mathrm{g}$ ), the $\mathrm{pH}$ value ranges from 5 to 9 , which was wider than other complexes ( $\mathrm{pH}$ value ranging from 4 to 6 ) and can be used in an alkaline environment.

\section{Acknowledgements}

This work was supported by the Geping Green Actionenvironmental Research and Education "123 Project" of Liaoning Province, China (CEPF2011-123-1-1), the National Natural Science Foundation of China (21277150), and the State Scholarship Fund organized by the China Scholarship Council (CSC2013). The authors would also like to thank Doc. Xiaoman Yu for her constant support.

\section{References}

1. ABOLLINO O., ACETO M., MALANDRINO M., SARZANINI C., MENTASTI E. Adsorption of heavy metals on Na-montmorillonite. Effect of $\mathrm{pH}$ and organic substances. Water Res. 37, 1619, 2003.

2. MISSANA T., GARCIA-GUTIERREZ M. ALOGSO U. Sorption of strontium onto illite/smectite mixed clays. Phys. Chem. Earth. 33, S156, 2008.

3. THENG B.K.G. Interactions between montmorillonite and fulvic acid. Geoderma, 15, 243, 1976.
4. CAMPBELL G.D., GALICIA H.F., SCHINDLE P. W. Binding of cadmium by montmorillonite humic acid mixtures-Miscible displacement experiments. Soil Res. 25, 391, 1987.

5. GUPTA S.S., BHATACHARYYA K. G. Adsorption of heavy metals on kaolinite and montmorillonite: a review. Phys Chem Chem Phys. 14, 6698, 2012.

6. ÖZDEMIE G., YAPAR S. Adsorption and desorption behavior of copper ions on Namontmorillonite: Effect of rhamnolipids and pH. J. Hazard. Mater. 166, 1307, 2009.

7. WANG K., XING B. Structural and sorption characteristics of adsorbed humic acid on clay minerals. J Environ Qual. 34, 342, 2005.

8. WU P.X., WU W.M., LI S.Z., XING N., ZHU X.W., LI P., WU J.H., YANG C., DENG Z. Removal of $\mathrm{Cd}^{2+}$ from aqueous solution by adsorption using Fe-montmorillonite. J. Hazard. Mater. 169, 824, 2009.

9. ABATE G., MSDINI J. C. Influence of $\mathrm{pH}$, ionic strength and humic acid on adsorption of $\mathrm{Cd}$ (II) and $\mathrm{Pb}$ (II) onto vermiculite. Colloids Surf A Physicochem Eng Asp. 262, 33, 2005.

10. LIU A., GONZALEZ R.D. Adsorption/desorption in a system consisting of humic acid, heavy metals, and clay minerals. J Colloid Interface Sci. 218, 225, 1999.

11. BHATTACHARYYA K.G., GUPTA S.S. Adsorption of a few heavy metals on natural and modified kaolinite and montmorillonite: a review. Adv. Colloid Interface Sci. 140, 114, 2008.

12. BORGNINO L., AVENA M.J., DE PAULI C.P. Synthesis and characterization of $\mathrm{Fe}(\mathrm{III})$-montmorillonites for phosphate adsorption. Colloids Surf., A: Physicochem. Eng. Aspects. 341, 46, 2009.

13. VAZQUEZ A., LOPEZ M., KORTABERRIA G., MARTIN L., MONDRAGON I. Modification of montmorillonite with cationic surfactants. Thermal and chemical analysis including CEC determination. Appl. Clay Sci. 41, 24, 2008.

14. ARIAS M., BARRAL M.T., MEJUTO J C. Enhancement of copper and cadmium adsorption on kaolin by the presence of humic acids. Chemosphere. 48, 1081, 2002.

15. LIPPOLD H, LIPPMANN-PIPKE J. Effect of humic matter on metal adsorption onto clay materials: Testing the linear additive model. J Contam Hydrol. 109, 40, 2009.

16. BELGHITI E., EL M'RABET M., MOUNTACER H., EL HOURCH A., ZRINEH A., EL AZZOUZI M. The effect of $\mathrm{Cu}$ and $\mathrm{Cu}$-humic acids on the adsorption of imazethapyr herbicide by montmorillonite clay. Biotechnol. Agron. Soc. Environ. 14, 659, 2010.

17. BAKE H., KHALILI F. Analysis of the removal of lead (II) from aqueous solutions by adsorption onto insolubilized humic acid: temperature and $\mathrm{pH}$ dependence. Anal Chim Acta. 516, 179, 2004.

18. WU X.L., ZHAO D., YANG S.T. Impact of solution chemistry conditions on the sorption behavior of $\mathrm{Cu}$ (II) on Lin'an montmorillonite. Desalination. 269, 84, 2011.

19. ZHU J., PIGNA M., COZZOLINO V., CAPORALE A.G., VIOLANTE A. Competitive sorption of copper (II), chromium (III) and lead (II) on ferrihydrite and two organomineral complexes. Geoderma. 159, 409, 2010.

20. BROWN L., SEATO K., MOHSENI R., VASILIEV A. Immobilization of heavy metals on pillared montmorillonite with a grafted chelate ligand. J. Hazard. Mater. 261, 181, 2013. 
